\title{
Load Shedding Control Strategy Based on Transient Instability Evaluation of Power System Using Artificial Neural Network and Analytic Hierarchy Process Algorithm
}

\author{
Nghia Le Trong 1, *, Au Nguyen Ngoc ${ }^{1}$, Anh Quyen Huy', and Binh Phan Thi Thanh ${ }^{2}$ \\ 1 Faculty of Electrical and Electronics Engineering, Hochiminh city University of Technology and Education, \\ Hochiminh City, Vietnam; \\ 2 Faculty of Electrical and Electronics Engineering, Hochiminh city University of Technology, Hochiminh \\ City, Vietnam; \\ * Correspondence: trongnghia@hcmute.edu.vn; Tel.: +84-283-896-0985
}

\begin{abstract}
Emergency control load-shedding is a key solution to prevent blackouts in the power system. This paper proposed a new model of emergency controls load shedding based on the fast identification of the unstable state of the power system. K-means clustering algorithm divided the instability mode into the clusters. The results of analysis of this cluster were used as the basis for classification control. Building load shedding strategies is consisted of the pre-designed rules based on AHP algorithm. When the recognition of the power system "instability" is detected, the signal of load shedding control is triggered immediately, therefore the decision time is greatly shortened comparing to the traditional methods. The effectiveness of the proposed method was tested on the IEEE 39-bus to overcome the limitations of the last traditional methods.
\end{abstract}

Keywords: emergency control; load shedding; artificial neural network; dynamic power system stability

\section{Introduction}

The large disturbances causing the instability need to be detected quickly to make the emergency control decision to take electrical system reverts to the stable, avoid the black out. Load shedding is considered as one of the methods to be applied in the emergency situations to help prevent instability and restore the factors of the power systems to be returned to the permissible limits. Most of the load shedding studies were under frequency load shedding (UFLS) to prevent the declining frequency when the electrical system was faulted [1-4]. The under frequency load shedding relays were set to shed a fixed amount that has been pre-determined in 3-5 steps when the frequency is below the threshold settings to keep the system stable. To improve the effectiveness of the load shedding, some load shedding methods are based on the showing the effectiveness of the proposed method.

\section{Materials and Methods}

\subsection{Pattern Recognition}

The classifier-based dynamic stability power system (DSP) can be formulated as a mapping $\mathrm{y}_{\mathrm{i}}=\mathrm{f}\left(\mathrm{x}_{\mathrm{i}}\right)$ after learning from a dynamic stability database $D=\left\{x_{i}, y_{i}\right\}_{i=1}^{n}$, where $\mathrm{x}_{\mathrm{i}}$ is feature; it is $\mathrm{n}$ dimensional input vector that characterizes the system operating states; and $\mathrm{yi}_{\mathrm{i}}$ is output vector. 


\subsection{Variables and samples}

For building the classifier for DSP classification, the initial features and samples are required. A large number of samples are generated through off-line simulation from the power system diagram. The stable and unstable status were evaluated for each fault under the study. Data for each bus and line fault occurring in the test systems are recorded in which samples of data are kept in a database.

The input is the vector of system state parameters characterizing the current system state. The fault-on features are variables characterizing faults of power system, such as voltage drops in the nodes $\left(\Delta \mathrm{V}_{\text {bus }}\right)$, changes in power flows in transmission line $\left(\Delta \mathrm{P}_{\text {flow }}\right)$, changes in load powers $\left(\Delta \mathrm{P}_{\text {load }}\right)$.

Vector output features represent the stable conditions of the power system. If the angle of the relative rotor generators is larger than $180^{\circ}$ then the system is 'Unstable', and less than $180^{\circ}$ then the system is 'Stable'. The corresponding data will be put into Unstable and Stable class. The output variables are assigned to label binary variable $y\{10,01\}$. Class $1\{10\}$ is Stable class and class $2\{01\}$ is Unstable class. The data is normalized before training.

\subsection{The feature selection}

This is an example of an equation: The feature selection is consisted of selecting a $d$ dimensional feature vector $z$. Where $d<n$; The $d$ selected features represent the original data in a new knowledge base $D_{\text {new }}=\left\{z_{i}, y_{i}\right\}_{i=1}^{d}$, and the new mapping $\mathrm{ynewi}=\mathrm{f}_{\text {new }}\left(\mathrm{Zi}_{\mathrm{i}}\right)$.

This process is included the steps: identifying variable sets and initial data, selecting the variable sets, evaluating the variable set [5-6]. In this paper, we introduce two standards to select variables: Fisher standard and Scatter matrices standard.

Fisher Standard: This is a simple method that is applied to select the specific variables [7,8]. Fisher standard is selected variables such as equation (1), the variable has a F larger value is more important.

$$
F(w)=\frac{\left|m_{1}-m_{2}\right|^{2}}{\sigma_{1}^{2}+\sigma_{2}^{2}}
$$

Where: $m_{i}$ is the average value of the class $C_{i}$ and $\sigma^{2}{ }_{i}$ is the variance of the class $C_{i}$.

Scatter matrices standard: Following the Scatter Matrices theory, the layer separation of the variable sets was measured by the objective function J according to equation (2).

$$
\mathrm{J}=\operatorname{Tr}\left\{\mathrm{S}_{\mathrm{w}}^{-1} \mathrm{~S}_{\mathrm{m}}\right\}
$$

where: $S_{m}$ is the sample covariance matrix; $S_{w}$ is within-class scatter matrix; The trace (Tr) of matrixes the sum of the diagonal elements.

J of equation (2) is the target value to help lead the way for the variable set search algorithm. The bigger J value of variable group is, the more important variable group is.

This paper applied two selected variables algorithm: variable ranking method based on the Fisher standard and Sequential Floating Forward Search (SFFS) algorithm. We introduced two methods and applied to the previously published papers [6].

\subsection{Data clustering}

K-means is clustering algorithm which is represented by a central of the elements in the cluster. This method is based on measuring the distance of the data objects in the clusters. K-means algorithm created $k$ data clusters $\left\{C_{1}, C_{2}, \ldots, C_{k}\right\}$ from a data set containing $N$ samples in d-dimensional space $X_{i}=\left\{x_{i 1}, X_{i 2}, \ldots, X_{i d}\right\}, i=[1, N]$, so that the standard functions reached the minimum value. Thus, K-means need to initiates a set of $\mathrm{k}$ center, and through which algorithm repeats these steps: assigns each object to the cluster that near the center, and recalculates center of each cluster on the basis of a new assignment for objects. The process stops when the centers do not change. Standard deviation squared, or De objective function is defined as follow:

$$
\mathrm{D}_{\mathrm{E}}=\sum_{\mathrm{i}=1}^{\mathrm{k}} \sum_{\mathrm{j}}^{\mathrm{n}}\left\|\mathrm{x}_{\mathrm{j}}-\mathrm{m}_{\mathrm{i}}\right\|^{2}
$$




$$
\mathrm{m}_{\mathrm{i}}=\frac{\sum_{\mathrm{l}=1}^{\mathrm{n}_{\mathrm{i}}} \mathrm{x}_{l}}{\mathrm{n}_{\mathrm{i}}}
$$

Where: $\mathrm{m}_{\mathrm{i}}$ is the cluster centroid; $\mathrm{x}_{\mathrm{j}}$ is the data vectors in the group $\mathrm{p} ; \mathrm{n}_{\mathrm{i}}$ is the number of data vectors in the group $p ;|1.1|$ is Euclidean distance.

$\mathrm{K}$-means algorithm is presented as follows:

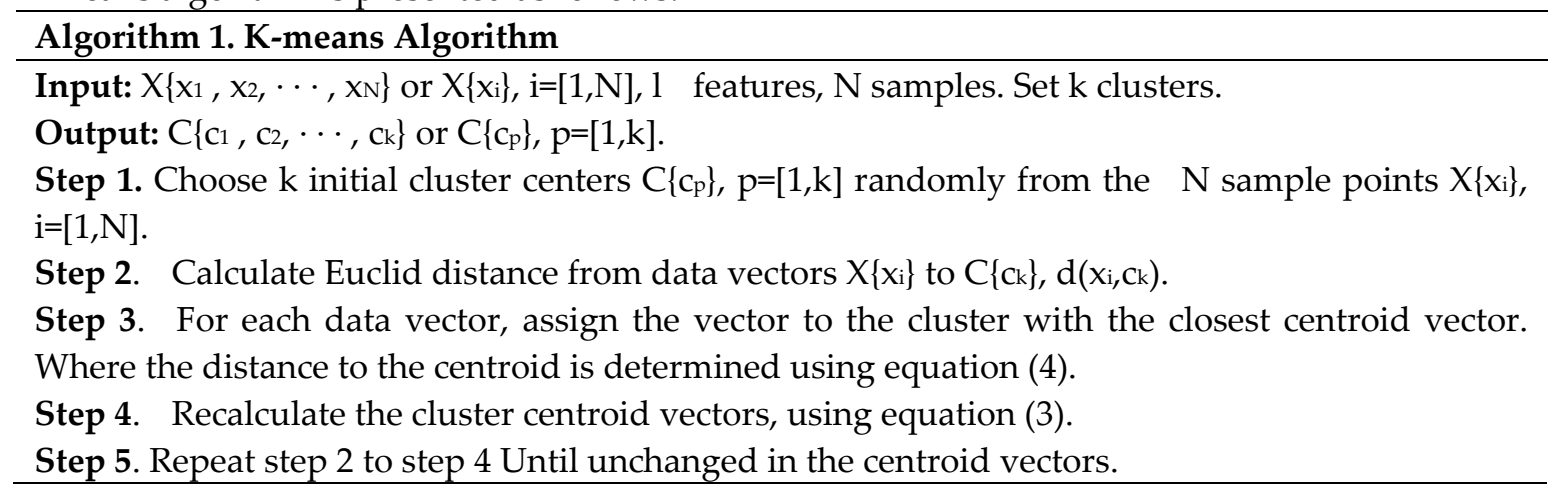

Accuracy training and test are calculated by the equation:

$$
r(\%)=\frac{n_{r}}{N} .100
$$

Where: $\mathrm{n}_{\mathrm{r}}$ is the number of training samples (or test) correct. $\mathrm{N}$ is the total number of training samples (or check).

\subsection{Time delay for load shedding}

In the power system stability study, load shedding time delay tshed is a very important role. $T_{\text {shed }}$ this period can lead to stability or instability system. Impact time of under-frequency load shedding relay (UFLS) is around 0.1s [9], and the process is performed until recovery frequency to the allowed value. In some emergency controls: short circuit, loss of generator, this method cannot maintain power system stability or recovery frequency for a long time. Application intelligent computing technology, load shedding period of time is required to implement the value smaller than $500 \mathrm{~ms}$ [10]. In this paper, it is $200 \mathrm{~ms}$, including: measurement and data acquisition, data transmission, data processing, and the impact circuit breaker. However, to ensure the safety margin in real time, as well as tolerance, the period time $100 \mathrm{~ms}$ was added [10]. So that, when performing simulation, the time $300 \mathrm{~ms}$ to cut the load was recommended.

\subsection{Analytic Hierarchy Process Algorithm}

Analytic Hierarchy Process Algorithm (AHP) [11] is determined the important factor of the load centers and load unit in the system, is performed by following these steps:

- $\quad$ Step 1: Identify the Load Center LC $\mathrm{i}_{\mathrm{i}}[10]$ and the Load Unit Li.

- Step 2: Set up a decision hierarchy model AHP including the Load Center and the Load Unit. 


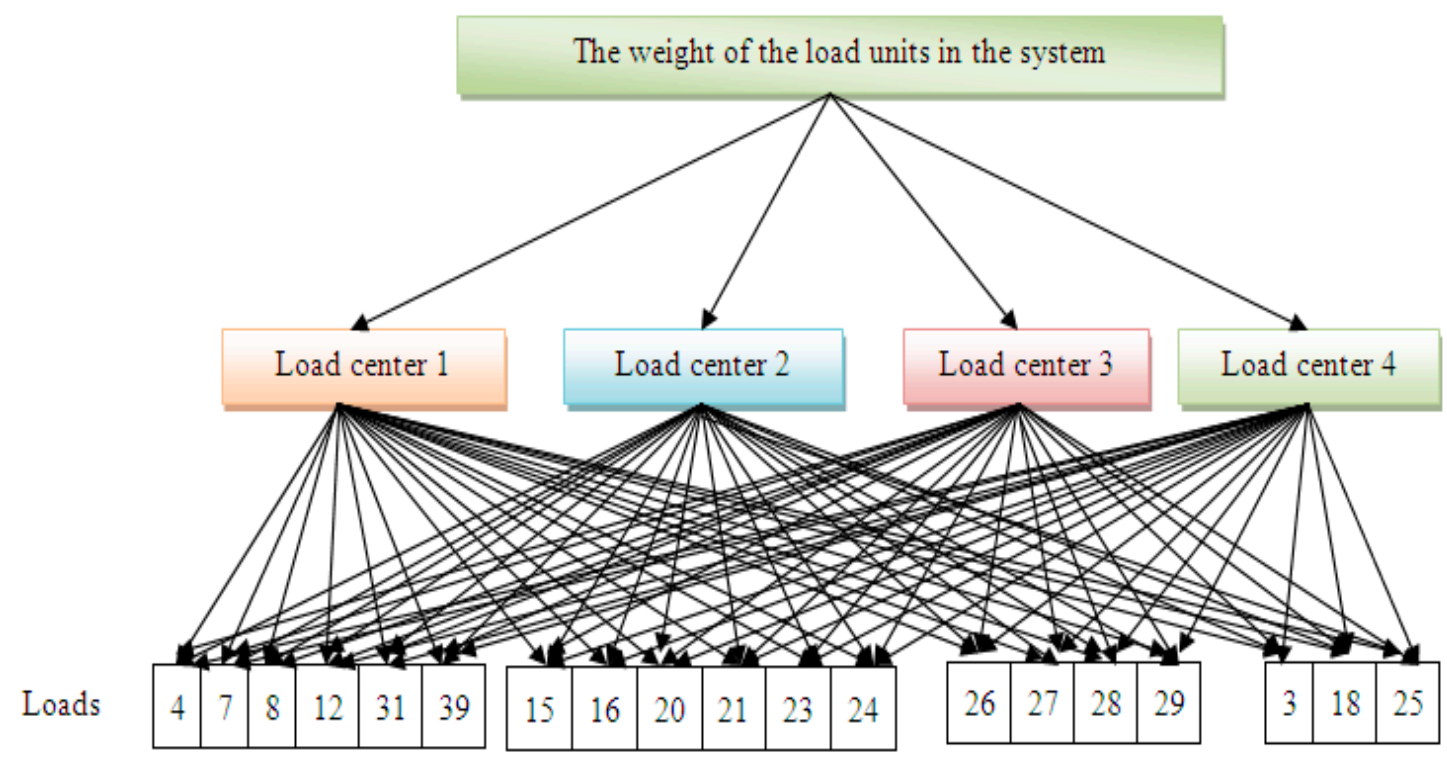

Figure 1. Analytic Hierarchy Process scheme

- $\quad$ Step 3: Build judgment matrix LC and Li showing the important factor between load centers (LC) and load units $(\mathrm{Li})$ each other of the power system. The value of elements in the judgment matrix reflects the user's knowledge about the relative importance between every pair of factors.

$$
\begin{aligned}
L C & =\left[\begin{array}{l}
\mathrm{w}_{\mathrm{K} 1} / \mathrm{w}_{\mathrm{K} 1} \mathrm{w}_{\mathrm{K} 1} / \mathrm{w}_{\mathrm{K} 2} \ldots . . \mathrm{w}_{\mathrm{K} 1} / \mathrm{w}_{\mathrm{Kn}} \\
\mathrm{w}_{\mathrm{K} 2} / \mathrm{w}_{\mathrm{K} 1} \mathrm{w}_{\mathrm{K} 2} / \mathrm{w}_{\mathrm{K} 2} \ldots . . \mathrm{w}_{\mathrm{K} 2} / \mathrm{w}_{\mathrm{Dn}} \\
\cdot \\
\cdot \\
\cdot \\
\mathrm{w}_{\mathrm{Kn}} / \mathrm{w}_{\mathrm{K} 1} \mathrm{w}_{\mathrm{Kn}} / \mathrm{w}_{\mathrm{K} 2} \ldots . . \mathrm{w}_{\mathrm{Kn}} / \mathrm{w}_{\mathrm{Kn}}
\end{array}\right] \\
L_{i} & =\left[\begin{array}{l}
\mathrm{w}_{\mathrm{D} 1} / \mathrm{w}_{\mathrm{D} 1} \mathrm{w}_{\mathrm{D} 1} / \mathrm{w}_{\mathrm{D} 2} \ldots . . \mathrm{w}_{\mathrm{D} 1} / \mathrm{w}_{\mathrm{Dn}} \\
\mathrm{w}_{\mathrm{D} 2} / \mathrm{w}_{\mathrm{D} 1} \mathrm{w}_{\mathrm{D} 2} / \mathrm{w}_{\mathrm{D} 2} \ldots . . \mathrm{w}_{\mathrm{D} 2} / \mathrm{w}_{\mathrm{Dn}} \\
\cdot \\
\cdot \\
\cdot \\
\mathrm{w}_{\mathrm{Dn}} / \mathrm{w}_{\mathrm{D} 1} \mathrm{w}_{\mathrm{Dn}} / \mathrm{w}_{\mathrm{D} 2} \ldots . . \mathrm{w}_{\mathrm{Dn}} / \mathrm{w}_{\mathrm{Dn}}
\end{array}\right]
\end{aligned}
$$

where, $\mathrm{WDi}_{\mathrm{i}} / \mathrm{WDj}_{\mathrm{Dj}}$ is the relative importance of the $i$ th load node compared with the $j$ th load node; $W_{\mathrm{ki}} / \mathrm{W}_{\mathrm{kj}} \mathrm{is}$ the relative importance of the $i$ th load center compared with the $j$ th load center. The value of $\mathrm{W}_{\mathrm{ki}} / \mathrm{W}_{\mathrm{kj}}, \mathrm{WDi}_{\mathrm{i}} / \mathrm{WDj}_{\mathrm{Dj}}$ can be obtained according to the experience of electrical engineers or system operators by using some " $1-9$ " ratio scale methods.

- Step 4: Calculate the important factor of the load central and the load units in the same area based on the judgment matrix.

- $\quad$ Step 5: Calculate the weighted importance of the load unit in the system.

According to the principle of AHP, the weighting factors of the loads can be determined through the ranking computation of a judgment matrix, which reflects the judgment and comparison of a series of pair of factors. The weighting importance of the load units of the system is calculated by multiplying the weights of the load nodes with the weight of the corresponding load center. Therefore, the unified weighting factor of the load nodes of the power system can be obtained from the following equation:

$$
W_{i j}=W_{k j} \times W_{D i} \quad D_{i} \in K_{j}
$$

where, $\mathrm{D}_{i} \in \mathrm{K}_{j}$ means load node $\mathrm{D}_{i}$ is located in load center $\mathrm{K}_{j}$. 
- $\quad$ Step 6: Sort by descending order of importance of each load unit in order to implement the load shedding strategy by priority upon unstable signal from the identification.

\section{The proposed model}

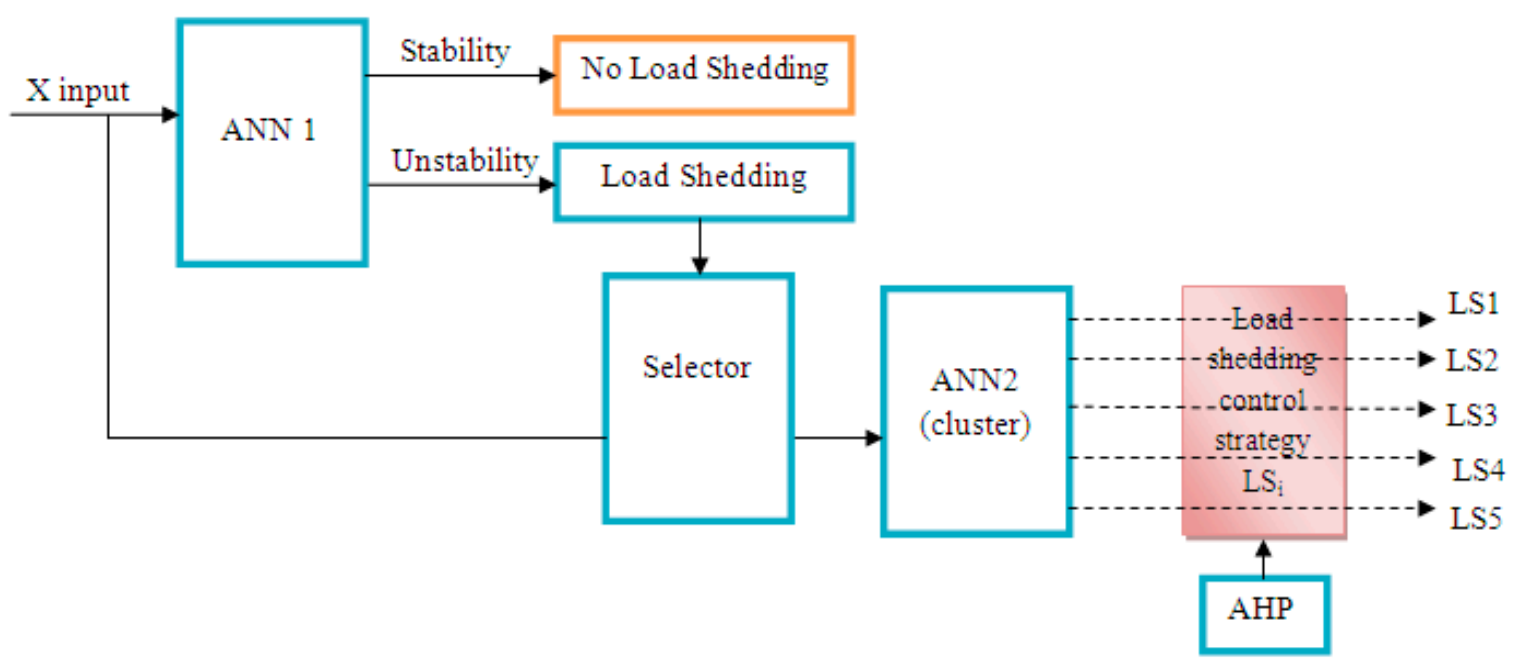

Figure 2. Online diagram emergency control of load shedding

The model is consisted of blocks:

- Input Variables: Input signal: $\Delta \mathrm{P}_{\text {load, }} \Delta \mathrm{V}_{\text {bus, }}$ and $\Delta \mathrm{P}_{\text {flow }}$ when the incident was occurred and were taken from the measurement device to quickly identify the instability of power system in case of incidents.

- The ANN1 identifier: received signals from input variables and output variable indicates that the system "Stability" or "Instability". When the system was "Instability", load shedding was implemented based on rules-based or based on strategy control that were classified.

- The ANN2 identifier: do classification to control: apply K-means clustering algorithm to cluster instability data into clusters and as a basis for building load shedding strategy. Thus, the input data of ANN2 was the data that was clustered by K-means algorithm. ANN2 received input variables when the output of ANN1 was "Instability" and the ANN2 output was the load shedding control strategies. Output matrix was calculated according to law of large numbers.

- The load shedding control strategy LSi: consist of load shedding strategies based on AHP algorithm to cut the loads according to priority. The program will cut load that has the low important factor before. It is contributed to reducing the damage when the problem is occurred. The flowchart is shown in Figure 3. 


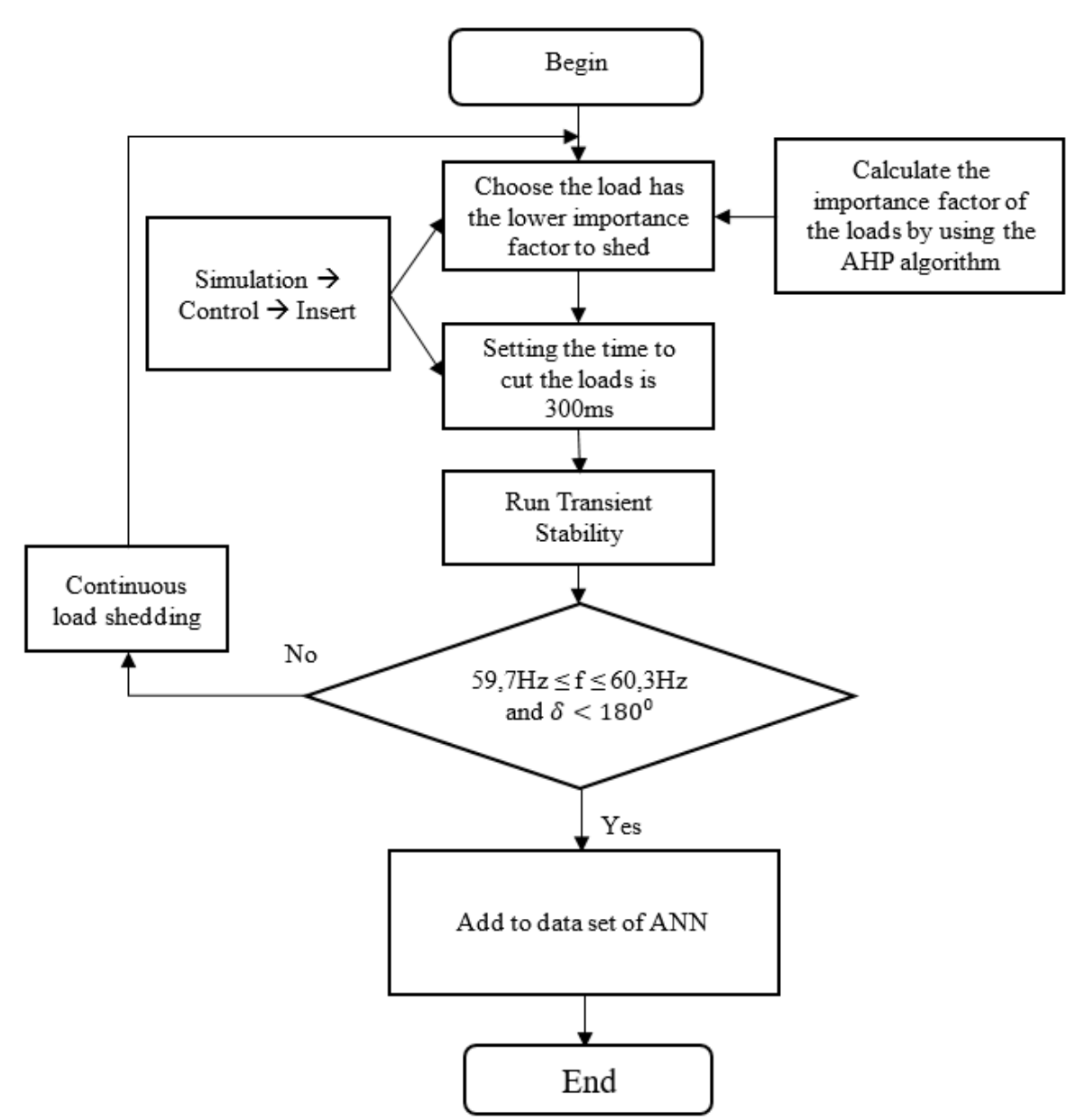

Figure 3. Offline flowchart to build load shedding emergency control strategies

\section{4. $\quad$ Results}

\subsection{Variables and initial samples}

In this section, the proposed model was tested on the IEEE 39 bus system, 10 generators, $60 \mathrm{~Hz}$ frequency was shown in Figure 4. 


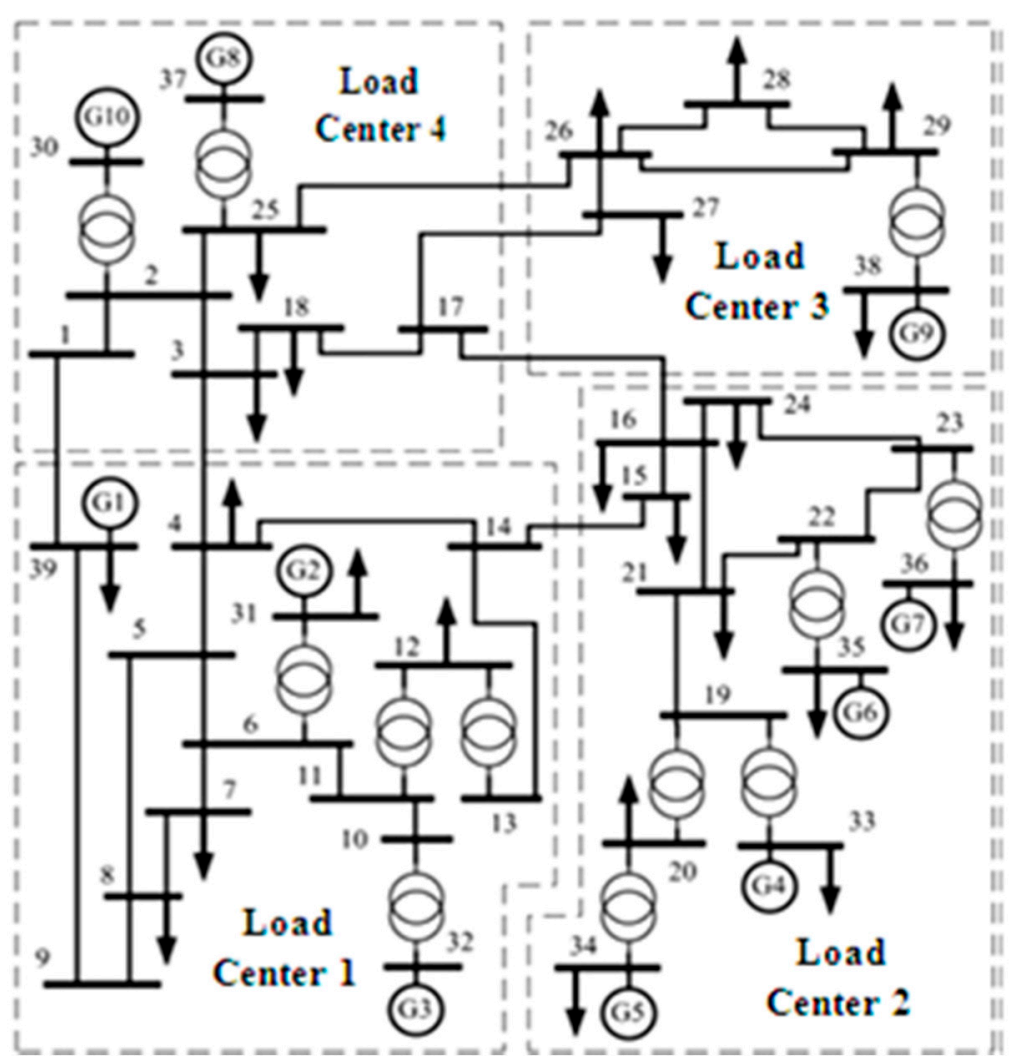

Figure 4. IEEE 39 bus system

PowerWorld software calculated corresponding generation capacity through Optimal Power Flow OPF computational tools. Off-line simulation to data acquisition evaluated the power system dynamic stability at $100 \%$ load, the circuit breaker short-time delay setting is $50 \mathrm{~ms}$. This paper reviewed the three-phase short-circuit problem, phase to ground, two-phase at all bus and along the transmission line for each of the $5 \%$-line length. Variables input and variables output are: $x\left\{\Delta \mathrm{V}_{\text {bus }}\right.$ $\left.\Delta \mathrm{P}_{\text {load, }} \Delta \mathrm{P}_{\text {flow }}\right\}$ and $\mathrm{y}\{1,0\}$. Total number of input variables are 104 (consist $\left.39+19+46\right), 1$ output variable $\{1,0\}$.

To proceed select variables, data sets were randomly divided into 10 subsets of equal size. Each of training set had 142 stability samples and 137 instability samples, the test set had 16 stability samples and 15 instability samples. The results of training and test were calculated the average for 10 times. This paper applied the K-NN (K-Nearest Neighbor) with $\mathrm{K}=1$ to evaluate the accuracy of variable set, and the accuracy evaluation results was presented in Figure 5.

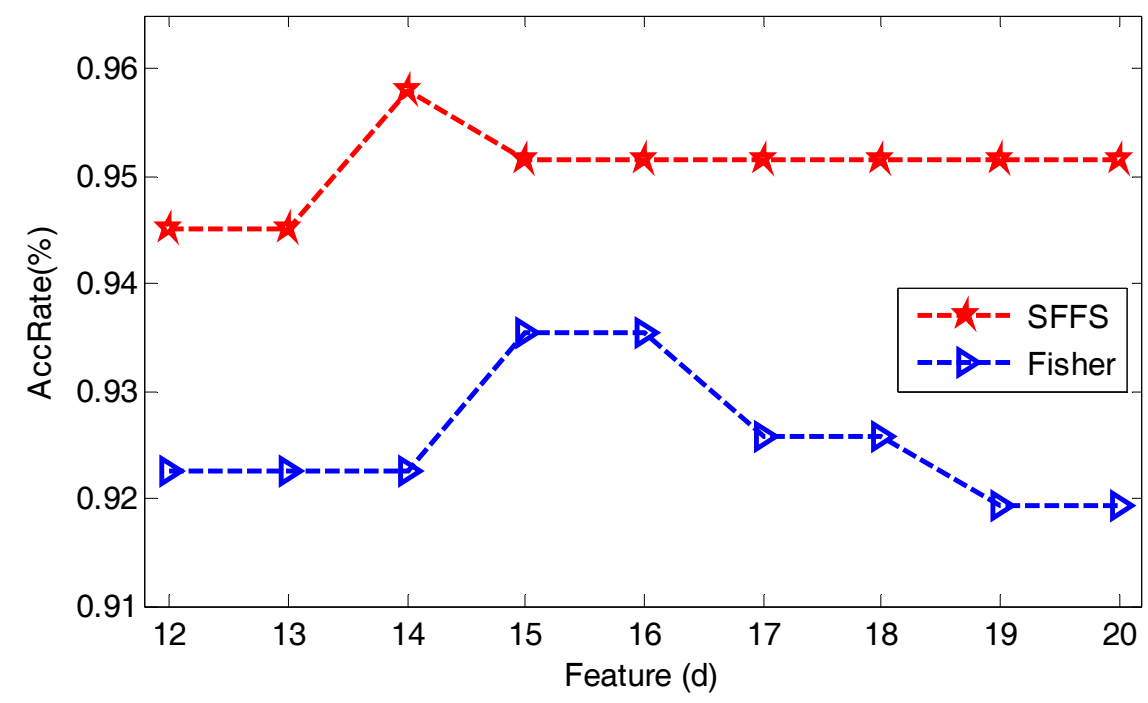

Figure 5. The accuracy of the selected variables, the identifier K-NN (K=1) 
From the results of Figure 5, the test precision when selecting the Fisher method is 93.5\% and the SFFS is $95.8 \%$ respectively with 15 and 14 variables. Since then, the number of selected variables with the SFFS method were 14 variables.

With 14 selected variables, training neural network with tools ANN1 neural network was supported by the Matlab software. Configuration and perceptron neural network parameters included 3 layers: input layer, hidden layer and output layer. Weighting update algorithm and Levenberg-Marquardt bias was recommended by fast calculation $[5,6,12]$. There are 152 sets of information in the neural network database, $70 \%$ of this information is used for training, $15 \%$ for testing, and $15 \%$ for cross-validation.

The number of training cycle was 1000, training errors was 1e-5, other parameters were default. The parameter setting, data training dividing and the test data were the same for ANN1 and ANN2: 14 inputs, used purelin activation function, tansig hidden function with 10 hidden layer neural, a neural output layer with ANN1 and 5 neural output layer with ANN2.

\subsection{Results data clustering}

Case study selected 5 load shedding control strategies corresponding to 5 instability data clusters. K-means

algorithm clustered 152 instability samples into 5 Clusters which consisted of samples were shown in Table 1.

Table 1. Results instability data clustering

\begin{tabular}{ccccc}
\hline \multicolumn{5}{c}{ Total instability samples: 152 } \\
\hline Cluster 1 & Cluster 2 & Cluster 3 & Cluster 4 & Cluster 5 \\
\hline 33 & 42 & 38 & 15 & 24 \\
\hline
\end{tabular}

Table 2. Results of the training and testing of two sets of identifier

\begin{tabular}{cccc}
\hline Input variables & Identifier & Accuracy of training (\%) & Accuracy of testing (\%) \\
\hline 14 & ANN1 & 97.1 & 95.4 \\
\hline 14 & ANN2 & 99.6 & 96.8 \\
\hline
\end{tabular}

\subsection{Calculation results of the load shedding strategic groups}

From the resulting of data clustering in Table 1, this paper proposed load shedding strategy for the 5 data clusters based on AHP algorithm.

Table 3. The load shedding strategies based on AHP algorithm

\begin{tabular}{ll}
\hline Control strategy & Load shedding \\
\hline LS1 & L31, L12 \\
\hline LS2 & L31, L12, L18 \\
\hline LS3 & L31, L12, L18, L26 \\
\hline LS4 & L31, L12, L18, L26, L23, L25 \\
\hline LS5 & L31, L12, L18, L26, L23, L25, L28 \\
\hline
\end{tabular}

\subsection{Simulation experiment in system}

Hereafter, the paper showed how to calculate the importance factor of the load based on AHP algorithm and load shedding simulation on the IEEE 39 bus system with the support of PowerWorld software for 2 incident cases are incident lines from Bus 29 to Bus 38 and incident at Bus 30.

\subsubsection{Calculate the important factor of the load based on AHP algorithm}

In the IEEE 39 bus system, the paper showed the steps of the algorithm AHP to build 4 load center and 19 units of load that were presented in Figure 4. Then, it built judgment matrix of the load 
center $\mathrm{LC}_{\mathrm{i}}$ and of the load $\mathrm{Li}_{\mathrm{i}}$ in the load center. The judgment matrix and calculation results the important factor of loads were presented in the Table $4 \div 9$.

Table 4. The judgment matrix of Load Centers

\begin{tabular}{lllll}
\hline & LC 1 & LC2 & LC3 & LC4 \\
\hline LC1 & $1 / 1$ & $4 / 1$ & $2 / 1$ & $5 / 1$ \\
\hline LC2 & $1 / 4$ & $1 / 1$ & $1 / 2$ & $2 / 1$ \\
\hline LC3 & $1 / 2$ & $2 / 1$ & $1 / 1$ & $3 / 1$ \\
\hline LC4 & $1 / 5$ & $1 / 2$ & $1 / 3$ & $1 / 1$ \\
\hline
\end{tabular}

Table 5. The judgment matrix of Load Units at Load Center 1

\begin{tabular}{llllll}
\hline & L3 & L4 & L18 & L25 & L39 \\
\hline L4 & $1 / 1$ & $1 / 2$ & $3 / 1$ & $2 / 1$ & $1 / 4$ \\
\hline $\mathbf{L 1 8}$ & $2 / 1$ & $1 / 1$ & $3 / 1$ & $2 / 1$ & $1 / 3$ \\
\hline $\mathbf{L 2 5}$ & $1 / 3$ & $1 / 3$ & $1 / 1$ & $1 / 2$ & $1 / 7$ \\
\hline L39 & $1 / 2$ & $1 / 2$ & $2 / 1$ & $1 / 1$ & $1 / 5$ \\
\hline
\end{tabular}

Table 6. The judgment matrix of Load Units at Load Center 2

\begin{tabular}{lllll}
\hline & L26 & L27 & L28 & L29 \\
\hline L26 & $1 / 1$ & $1 / 2$ & $1 / 2$ & $1 / 3$ \\
\hline $\mathbf{L 2 7}$ & $2 / 1$ & $1 / 1$ & $2 / 1$ & $1 / 1$ \\
\hline $\mathbf{L 2 8}$ & $2 / 1$ & $1 / 2$ & $1 / 1$ & $1 / 2$ \\
\hline
\end{tabular}

Table 7. The judgment matrix of Load Units at Load Center 3

\begin{tabular}{lllllll}
\hline & L15 & L16 & L20 & L21 & L23 & L24 \\
\hline L15 & $1 / 1$ & $1 / 1$ & $1 / 2$ & $2 / 1$ & $2 / 1$ & $1 / 1$ \\
\hline $\mathbf{L 1 6}$ & $1 / 1$ & $1 / 1$ & $1 / 2$ & $2 / 1$ & $2 / 1$ & $1 / 1$ \\
\hline $\mathbf{L 2 0}$ & $2 / 1$ & $2 / 1$ & $1 / 1$ & $3 / 1$ & $3 / 1$ & $2 / 1$ \\
\hline $\mathbf{L 2 1}$ & $1 / 2$ & $1 / 2$ & $1 / 3$ & $1 / 1$ & $1 / 1$ & $1 / 2$ \\
\hline $\mathbf{L 2 3}$ & $1 / 2$ & $1 / 2$ & $1 / 3$ & $1 / 1$ & $1 / 1$ & $1 / 1$ \\
\hline $\mathbf{L 2 4}$ & $1 / 1$ & $1 / 1$ & $1 / 2$ & $2 / 1$ & $1 / 1$ & $1 / 1$ \\
\hline
\end{tabular}

Table 8. The judgment matrix of Load Units at Load Center 4

\begin{tabular}{lllll}
\hline & L7 & L8 & L12 & L31 \\
\hline $\mathbf{L 7}$ & $1 / 1$ & $1 / 3$ & $8 / 1$ & $9 / 1$ \\
\hline $\mathbf{L 8}$ & $3 / 1$ & $1 / 1$ & $9 / 1$ & $9 / 1$ \\
\hline $\mathbf{L 1 2}$ & $1 / 8$ & $1 / 9$ & $1 / 1$ & $2 / 1$ \\
\hline $\mathbf{L 3 1}$ & $1 / 9$ & $1 / 9$ & $1 / 2$ & $1 / 1$ \\
\hline
\end{tabular}

Table 9. Arrange in order from descending of importance of the load units

\begin{tabular}{lll}
\hline Load Units & Order & Weight or Importance \\
\hline L39 & 1 & 0.256 \\
\hline L4 & 2 & 0.1009 \\
\hline L20 & 3 & 0.0827 \\
\hline L3 & 4 & 0.0722 \\
\hline L29 & 5 & 0.0511 \\
\hline L8 & 6 & 0.0496 \\
\hline L25 & 7 & 0.0483 \\
\hline L27 & 8 & 0.0462 \\
\hline L15 & 9 & 0.0455
\end{tabular}




\begin{tabular}{lll}
\hline L16 & 10 & 0.0455 \\
\hline L24 & 11 & 0.0406 \\
\hline L18 & 12 & 0.0291 \\
\hline L7 & 13 & 0.0278 \\
\hline L28 & 14 & 0.0275 \\
\hline L23 & 15 & 0.0268 \\
\hline L21 26 & 16 & 0.0239 \\
\hline L12 & 17 & 0.0176 \\
\hline L31 & 18 & 0.0051 \\
\hline
\end{tabular}

\subsubsection{The simulation results}

Considering in two cases the problem is short-circuit the transmission line from the bus 29 to bus 38 and short-circuit at bus 30. The circuit breaker of the line will open both ends of the line in case short-circuit from bus 29 to bus 38, and the circuit breaker link with the bus will open in case short-circuit at Bus 30. The simulation results for two cases made the system instability when the system was not load shedding. The change of rotor angle of generators and the frequency of system when incidents were shown in Figure 6 and Figure 7 for the case of short-circuit line from the bus 29 to bus 38 .

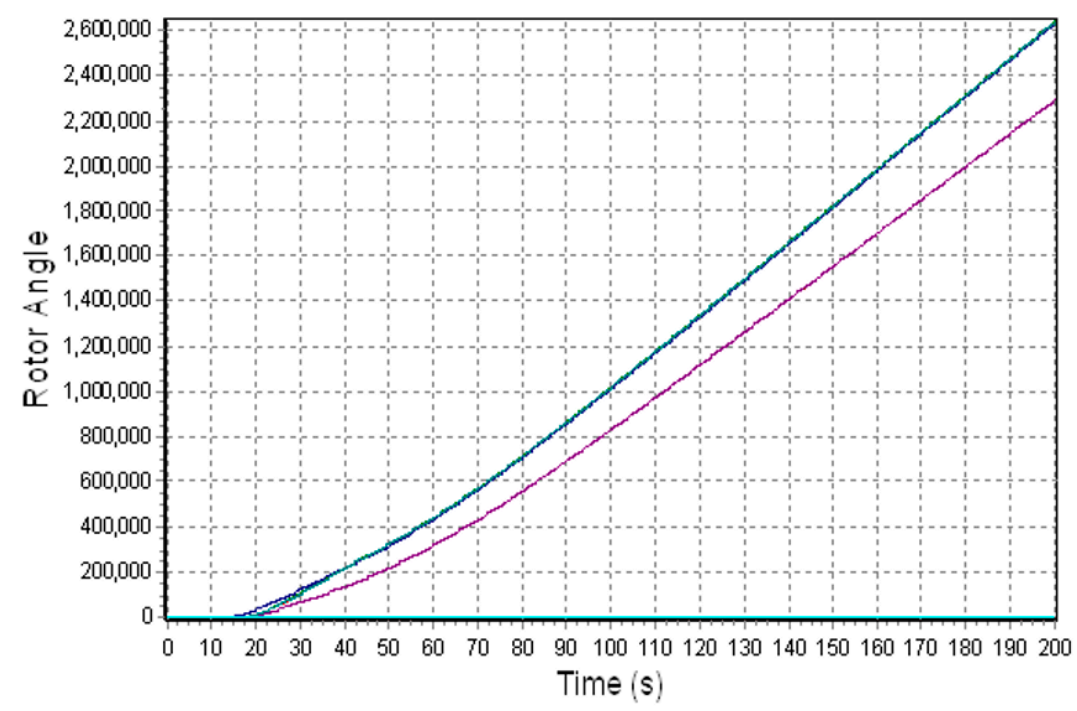

Figure 6. Rotor angle of the system when the line 29-38 was faulted

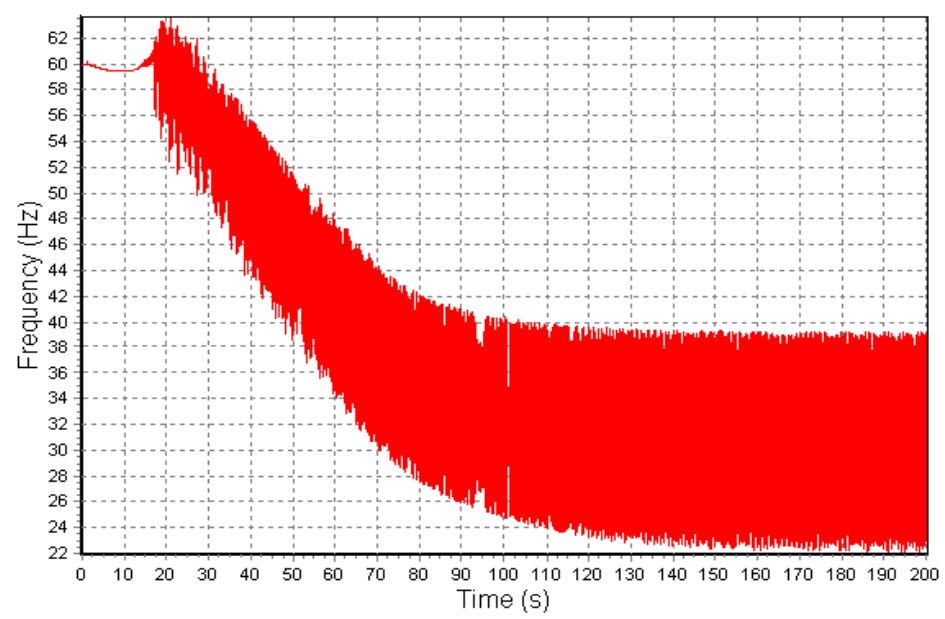

Figure 7. The frequency of the system when the line 29-38 was faulted 
Applying the proposed load shedding program, with this short-circuit situation, load shedding control strategy was LS4 which was executed, and the time delay was 300ms.

Observing the rotor angle, the system is recovered or stabled at the $15 \mathrm{~s}$ (Figure 8). The simulation and comparison results of the recovery frequency were shown in Figure 8 and Figure 9. Comparing with the under frequency load shedding relay method (UFLS) with the time began load shedding was about 3.9s after the incident, this time includes: time delay from the incident to frequency below $59.7 \mathrm{~Hz}$ was $3.7 \mathrm{~s}$, the processing time of relay UFLS was $0.1 \mathrm{~s}$, signal transmission and trip breakers were $0.1 \mathrm{~s}$.

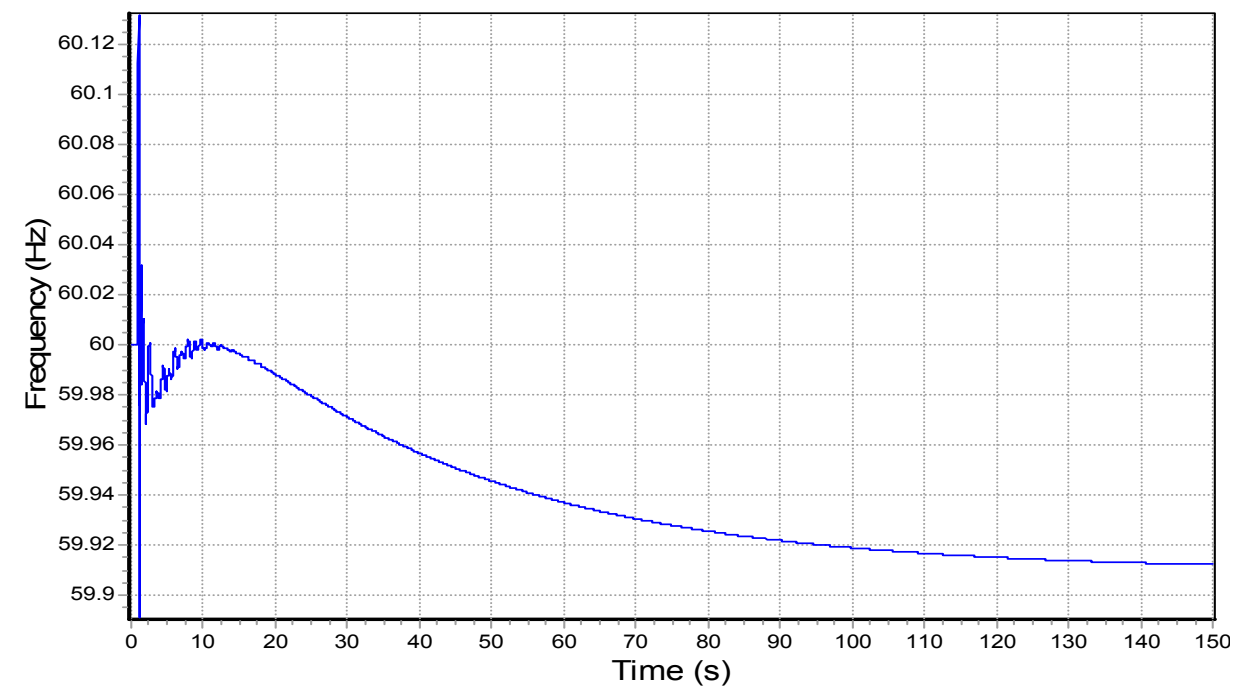

Figure 8. The frequency of the system after load shedding according to proposed method

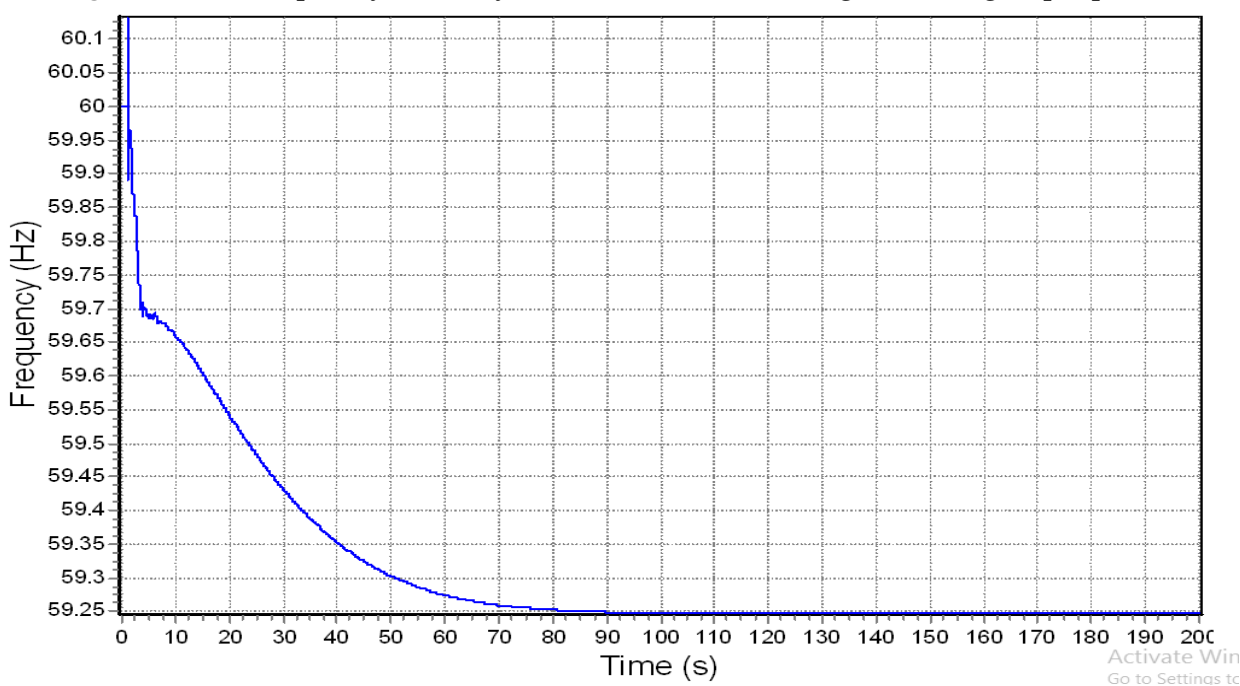

Figure 9. The frequency of the system after load shedding according to traditional method

The simulation results applied to proposed algorithm in case incident Bus 30, was shown in Figure 11. 


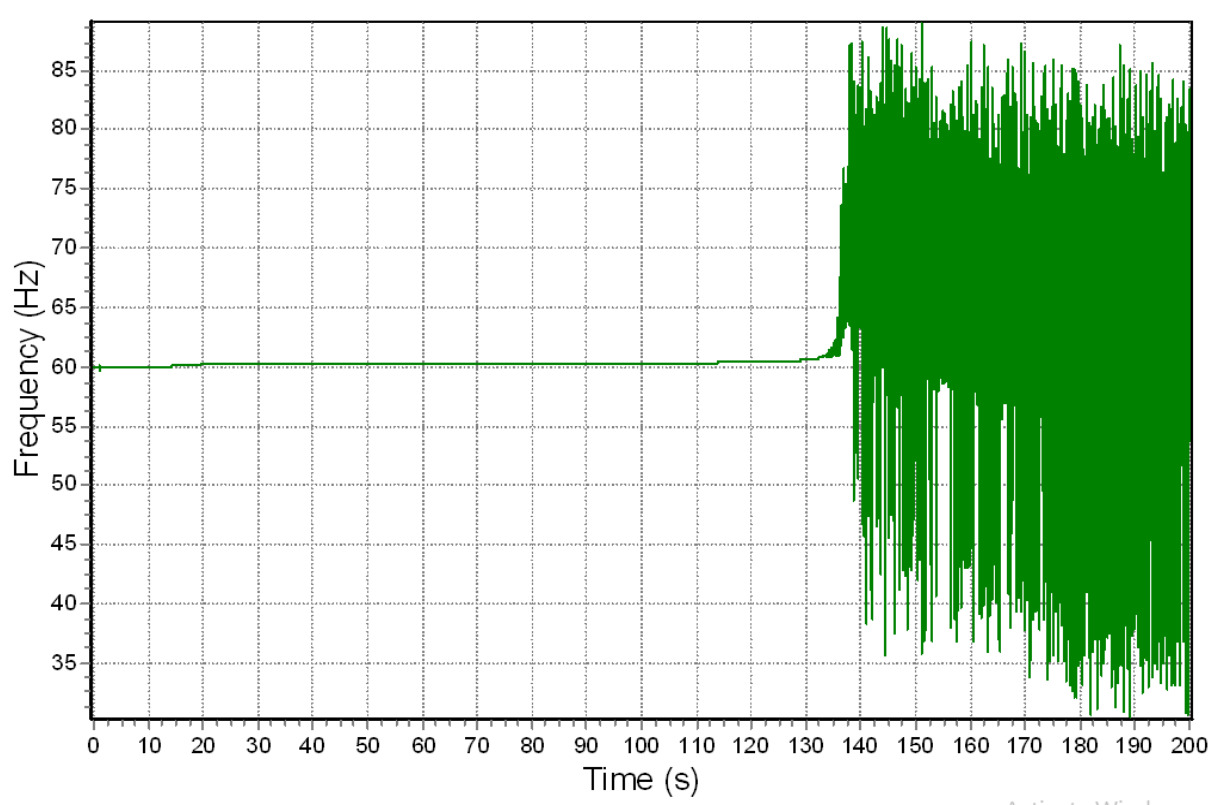

Figure 10. The frequency of the system after load shedding according to traditional methods

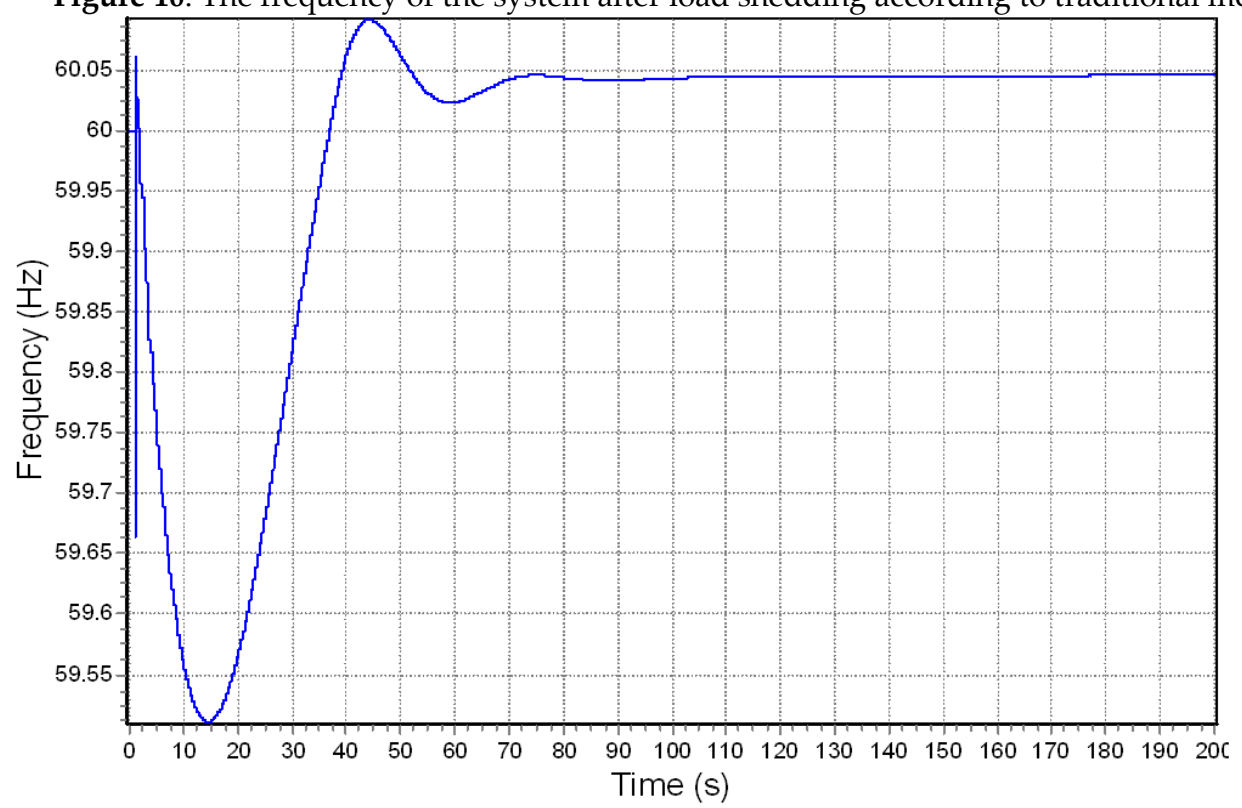

Figure 11. Frequency of the system after load shedding according to the proposed method

\subsubsection{Discussion}

In figure 5, with the K-NN recognition $(K=1)$, the results showed that the SFFS algorithm had the test results with higher accuracy Fisher method is $2.3 \%$ while the less than 1 variable. This showed that SFFS is expanded search space and chosen the better variables, number of variables is decreased to smaller than 13.5 times the initial number of variables.

Applying the K-means algorithm clusters initial instability data into 5 clusters of 152 samples corresponding to the 5 strategic load shedding. Accuracy test to identify these clusters were $96.8 \%$. In Table 2, the recognition accuracy of ANN2 and ANN1 were $95.4 \%$ and $96.8 \%$ respectively. This is an acceptable result with the previous study, and accuracy from $94 \%-97 \%[5,8]$.

The application of the proposed load shedding strategy keeping the system stable after the incident was shown in Figure 8 and Figure 10. The comparative results between the proposed method and the under-frequency load shedding relay methods were presented in Table 10. 
Table 10. Comparison of the recovery frequency of load shedding methods

\begin{tabular}{lll}
\hline & The proposed method & The UFLS relay \\
\hline $\begin{array}{l}\text { Frequency recovery value when line from bus } \\
\mathbf{2 9} \text { to bus } \mathbf{3 8} \text { was faults (Hz) }\end{array}$ & 59.91 \\
\hline $\begin{array}{l}\text { Frequency recovery value when bus } \mathbf{3 0} \text { was } \\
\text { faults (Hz) }\end{array}$ & & Instability \\
\hline
\end{tabular}

Thus, the proposed method helped accelerate the process of decision-making load shedding, and the time to impact on load shedding was reduced. This result showed that the frequency quality of the proposed method is better than the traditional methods, even in the cases of incident bus 30, it helped to keep the system stable.

\section{Conclusions}

This paper presented the process of developing an identification system to evaluate the instability state of power system and cluster the load shedding control strategy based on the two neural networks.

The proposed model based on neural network helped reduce the time to load shedding decision. Test results showed that the electrical system kept the state steady or stable. The quality of frequency values are restored faster and higher than the traditional methods.

K-means algorithm is combined with AHP algorithm built load shedding strategic clusters considering to the importance of the load, is contributed to reducing economic damage.

Acknowledgments: This research was supported by Ho Chi Minh City University of Technology and Education under a research at the Electrical Power System and Renewable Lab.

Author Contributions: Nghia.L.T., Au.N.N., Anh.H.Q., and Binh.P.T.T. conceived and designed the experiments; Nghia.L.T., and Au.N.N. performed the fast identification of the unstable state of the power system and built load shedding strategies; Nghia.L.T. performed the experiments; Nghia.L.T., and Au.N.N. analyzed the data; Binh.P.T.T. contributed materials tools; Nghia.L.T. wrote the paper with revision by Au.N.N., Anh.H.Q., and Binh.P. All authors agreed on the final version of the manuscript.

\section{Conflicts of Interest}

The authors declare no conflict of interest.

\section{References}

1. Terzija, V. V. Adaptive under frequency load shedding based on the magnitude of the disturbance estimation. IEEE Trans Power System 2006, Volume 21, No. 3, pp. 1260-1266, DOI: 10.1109/TPWRS.2006.879315.

2. Giroletti, M.; Farina, M.; Scattolini, R. A hybrid frequency/power based method for industrial load shedding. International Journal of Electrical Power \& Energy Systems 2012, Volume 35, pp. 194-200, DOI: 10.1016/j.ijepes.2011.10.013.

3. IEEE Guide for the Application of Protective Relay used for Abnormal Frequency Load Shedding and Restoration, IEEE StdC37. pp. 117-2007.

4. Adly A, Girgis.; Shruti Mathure. Application of active power sensitivity to frequency and voltage variations on load shedding. Electric Power Systems Research 2010, Volume 80, pp. 306-310, DOI: 10.1016/j.epsr.2009.09.013.

5. Zhang, R.; Member, S.; Xu, Y.; and Dong, Z. Y. Feature Selection for Intelligent Stability Assessment of Power Systems. IEEE Power and Energy Society General Meeting 2012, pp. 1-7, DOI: 10.1109/PESGM.2012.6344780.

6. Swarup, K. S. Artificial neural network using pattern recognition for security assessment and analysis. Neurocomputing 2008, Volume 71, no. 4-6, pp. 983-998, DOI: 10.1016/j.neucom.2007.02.017.

7. Hsu, C. T.; Kang, M. S.; and Chen, C. S. Design of adaptive load shedding by artificial neural networks. IEE Proc. Generation - Transmission and Distribution 2005, Volume 152, No. 3, pp. 415-421, DOI: 10.1049/ipgtd:20041207.

8. Bevrani, H.; Ledwich, G.; Ford, J. J. On the use of $\mathrm{df} / \mathrm{dt}$ in power system emergency control. Power Systems Conference and Exposition PSCE '09. IEEE/PES 2009, pp.1-6, DOI: 10.1109/PSCE.2009.4840173. 
9. Hooshmand, R.; and Moazzami M. Optimal design of adaptive under frequency load shedding using artificial neural networks in isolated power system. International Journal of Electrical Power \& Energy Systems 2012, Volume 42, No. 1, pp. 220-228, DOI: 10.1016/j.ijepes.2012.04.021.

10. Moein Abedini; Majid Sanaye-Pasand; Sadegh Azizi. Adaptive load shedding scheme to preserve the power system stability following large disturbances. IET Generation, Transmission E Distribution 2014, Volume 8, pp. 2124 - 2133, DOI: 10.1049/iet-gtd.2013.0937.

11. Zhu, J. Z. Optimal Load Shedding Using AHP and OKA. International Journal of Power and Energy Systems 2005, Volume 25, No.1, pp40-49, DOI: 10.2316/Journal.203.2005.1.203-3234.

12. Karami, A.; Esmaili, S. Z. Transient stability assessment of power systems described with detailed models using neural networks. International Journal of Electrical Power E Energy Systems 2013, Volume 45, no. 1, pp. 279-292, DOI: 10.1016/j.ijepes.2012.08.071

13. Laghari, J.A.; Mokhlis, H.; Bakar, A.H.A.; Hasmaini Mohamad. Application of computational intelligence techniques for load shedding in power systems: A review. Energy Conversion and Management 2013, Volume 75, pp130-140, DOI: 10.1016/j.enconman.2013.06.010.

14. Sasikala, J.; and Ramaswamy, M. Fuzzy based load shedding strategies for avoiding voltage collapse. Applied Soft Computing 2009, Volume 11, No. 3, pp. 3179-3185, DOI: 10.1016/j.asoc.2010.12.020.

15. Sadati, M.; Amraee, T.; and Ranjbar, A. M. A global particle swarm-based-simulated annealing optimization technique for under-voltage load shedding problem. Applied Soft Computing 2009, Volume 9, pp. 652-657, DOI: .1016/j.asoc.2008.09.005.

16. Tohid Sheraki; Farrokh Aminifar; Majid Sanaye-Pasand. An anatical adaptive load shedding scheme against sevre combinational disturbances. IEEE Transactions on Power Systems 2015, Volume 31, Issue: 5, pp. 4135 - 4143, DOI: 10.1109/TPWRS.2015.2503563.

17. Seyedi, H.; Sanaye-Pasand, M. Design of new load shedding special protection schemes for a double area power system. American Journal of Applied Sciences 2009, Volume 6, pp. 317-327, DOI: 10.3844/ajas.2009.317.327.

18. Urban Rudez; Rafael Mihalic. A novel approach to underfrequency load shedding. Electric Power Systems Research 2011, Volume 81, pp. 636-643, DOI: 10.1016/j.epsr.2010.10.020.

19. http://icseg.iti.illinois.edu/ieee-39-bus-system. Accessed Jan 2017. 